Ann. Zootech., I978, 27 (4), 6I7-630.

\title{
Valeur alimentaire d'un colza fourrager (Brassica napus, var. Oleifera) sur pied et après ensilage
}

\author{
Rollande DUMONT, A. RAIGE et J. L. TISSERAND
}

avec la collaboration technique de catherine CoRDFifT, F. FACRIF et A. MHRFino

\author{
Laboratoive de Recherches de la Chaire de Zootechnie, \\ Centre de Recherches de Dijon, I.N.R.A., \\ Scole Nationale Supérieure des Sciences Agronomiques Appliquées \\ 26, bd du Dr-Petitjean, B.P. 588 \\ 2Iol6 Dijon Cedex (France)
}

\section{Résumé}

Un colza fourrager, à cycle végétatif moyen (9o jours), de variété 'Tantal, non alternatif, est semé en dérobé début août, en 1975 et 1976 , en Côte-d'Or.

La digestibilité et l'ingestibilité du fourrage vert récolté de la I I ${ }^{e}$ à la I ${ }^{e}$ semaine de végétation et de l'ensilage réalisé aux $85^{\mathrm{e}}$ et roo $^{\mathrm{e}}$ jours de végétation sont mesurées sur des noutons.

Au cours des 5 semaines de mesures, la teneur en matière sèche de la plante verte augmente de r 2 à I 5 p. Ioo en I 975 , de ro à I 2 p. Ioo en 1976 . La composition chimique de la matière sèche est, en moyenne, la suivante : totales:

— en I975, I 5 p. Ioo de cendres, 16 p. roo de cellulose brute, ito p. Ioo de matières azotées totales.

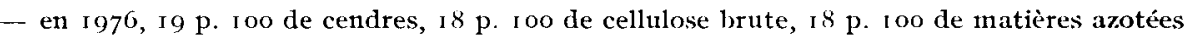

Les animaux ingèrent en moyenne $92 \mathrm{~g}$ de matière sèche par $\mathrm{kg} \mathrm{P}^{0,7 \pi}$. La digestibilité de la matière organique ne varie pas avec le stade de récolte; elle est de l'ordre de $82-83$ p. roo. En I975, la digestibilité des matières azotées totales diminue significativement avec le vieillissement de la plante (de 79 à 74 p. Ioo). Par contre, en 1976, elle est plus élevée qu'en I 975 (80 p. Iooen moyenne) et ne varie pas avec l'âge du fourrage.

La valeur énergétique est comprise entre 0,85 et 0,90 U.F. Breirem par $\mathrm{kg}$ de matière sèche. L,es teneurs en azote varient selon l'année et le stade de récolte de i io à $160 \mathrm{~g}$ de MAD par kg de matière sèche.

Les caractéristiques de l'ensilage sont satisfaisantes. Les pertes, au cours de la conservation, représentent $\mathrm{I} 4 \mathrm{p}$. I 00 et $35 \mathrm{p}$. I oo de la matière sèche respectivement en 1975 et 1976. L'ensilage entraîne une diminution faible de la digestibilité de la matière organique $(3,4$ points en 1975 , 0,8 en 1976) et une diminution plus importante et plus variable de l'ingestibilité $(7,6 \mathrm{p}$. Ioo en $1975,20 \mathrm{p}$. I oo en 1976 ). La valeur énergétique du $\mathrm{kg}$ de matière sèche d'ensilage est égale en moyenne à 0,83 U.F. Breirem, sa teneur en M.A.D. est comprise entre 1 ro et $14^{\circ} \mathrm{g}$. 


\section{Introduction}

Parmi les plantes susceptibles d'être exploitées en culture dérobée, le colza fourrager présente un certain nombre d'avantages :

- son cycle végétatif est relativement court, la variété Liho semée fin avril I 970 en Côte-d'Or produit $5,5 \mathrm{t}$ de matière sèche 70 jours environ après le semis (PIANCQUAERT, I972);

- il existe dans cette espèce, des variétés non alternatives intermédiaires entre les colzas d'hiver et de printemps qui montent mais ne fleurissent pas en culture annuelle; leur utilisation n'est donc pas limitée par la floraison; c'est le cas de Tantal;

- de plus, certaines variétés résistant à des températures de moins $8^{\circ} \mathrm{C}$, leur exploitation peut alors se poursuivre jusqu'au début de l'hiver.

On ne trouve dans la bibliographie que quelques données concernant la composition chimique de ce foutrage (BeCker et NeHRING, I969; PlancouaERT, I972; Piccioni, I965). Par contre, l'ingestibilité et la digestibilité sont mal connues surtout lorsque cette plante est utilisée sous forme d'ensilage. C'est pourquoi nous avons mesuré sur moutons, pendant deux années successives, la valeur alimentaire d'un colza fourrager récolté en vert ou conservé par ensilage.

\section{Matériel et méthodes}

\section{I. - Les fourrages}

-... L'étude est effectuée sur un colza fourrager de variété Tantal, non alternatif, à cycle de végétation d'une durée moyenne de go jours, cultivé en dérobé.

-- Le colza est mis en culture dans des parcelles du Domaine de la Station d'Amélioration des Plantes d'Époisses en Côte-d'Or, pendant deux années consécutives. Il est semé les 3 août 1975 et 2 août 1976 sur une défriche d'orge d'hiver, après déchaumage au cover-crop et hersage, aux doses de ro $\mathrm{kg}$ de semence par hectare la première année, $7 \mathrm{~kg}$ la seconde. La fumure de fond, Ioo unités d'acide phosphorique et de potasse, a été apportée pour l'orge et seule une fertilisation azotée sous forme de sulfate d'ammoniaque est épandue au moment du semis (6o unités en I975, I20 unités en I975). Celui-ci est suivi d'un seul arrosage en I975, de trois en 1976 .

-. Le colza est exploité en vert du $77^{\mathrm{e}}$ au I $2^{\mathrm{e}}$ jour après le semis. La hauteur des plantes varie de 30 à $70 \mathrm{~cm}$ selon 1'année et le lieu de récolte dans la parcelle. Chaque jour, les quantités récoltées et les surfaces fauchées sont enregistrées.

- L'ensilage est réalisé I02 jours après 1e semis à 13,8 p. IoO de matière sèche en I975, 85 jours après le semis à 10,6 p. Ioo de matière sèche en 1976 . La récolte est effectuée avec une ensileuse à fléaux. Le silo est situé sur une aire paillée en légère pente à l'abri sous un hangar. Il est constitué de 2 films de plastique, l'un étendu sur le sol, l'autre couvrant le fourrage, le tout maintenu par une couche de sable. Il est drainé. A la mise en silo, un vide partiel est créé au moyen d'une pompe. Un conservateur, 1 acide formique du commerce, est utilisé aux doses de 41 en I975, I, 51 en I976, dilués dans 201 d'eau, par tonne de fourrage vert.

Les quantités de matière sèche mises en silo puis retirées des silos sont pesées afin de déterminer les pertes au cours de la conservation. 


\section{Les animaux}

Les moutons utilisés sont des mâles castrés, âgés de plus de 3 ans, de race Ile-de-France, pesant de 60 à $80 \mathrm{~kg} ; 4$ animaux sont placés en case individuelle au sol, 4 en cage à métabolisme. Les mêmes animaux sont utilisés pour les mesures sur le fourrage vert et sur l'ensilage.

\section{Déroulement des essais}

Les animaux recevant antérieurement un fourrage vert, la phase d'accoutumance ne dure que 6 jours. Elle est suivie de 5 semaines de mesures. Le colza vert est récolté chaque matin, hâché dans un hâche-paille en brins de 2 à $3 \mathrm{~cm}$ de longueur, puis distribué à volonté (ro p. Ioo de refus) en 4 repas par jour.

Au cours des hivers I 975-76 et I 976-77, l'ensilage est donné à volonté (Io p. Ioo de refus) en 2 repas par jour. La période de mesure dure alors 3 semaines et est précédée par ro jours d'accoutumance. Avant cet essai, les animaux étaient déjà alimentés avec un fourrage ensilé.

\section{4. - Mesures}

Les quantités de matière sèche ingérées sont mesurées individuellement chaque jour, 5 jours par semaine, par pesée des quantités offertes et refusées (pesées à $5 \mathrm{~g}$ ) et détermination des teneurs en matière sèche du fourrage distribué et des refus (pesées à $0,5 \mathrm{~g}$ ). Chaque résultat correspond à la moyenne, sur la séquence des 5 jours, des consommations journalières individuelles des 8 moutons.

La digestibilité est mesurée sur les 4 animaux placés en cage à métabolisme; elle est calculée sur la même séquence de 5 jours.

En I975, les animaux sont pesés (double pesée) en début et fin d'expérience. Pour les calculs, les poids du début sont attribués à la première semaine, les poids de fin d'expérience à la dernière semaine et les moyennes de ces 2 poids aux semaines intermédiaires. En I976, les animaux sont pesés en début et fin d'expérience et une fois par semaine au cours de l'expérience.

\section{5. - Analyses}

Des prélèvements journaliers des fourrages verts et des ensilages offerts, des refus et des fèces sont effectués pour mesurer la teneur en matière sèche par séchage pendant 24 heures dans une étuve ventilée à $68^{\circ} \mathrm{C}$. Pour chaque mouton en cage à métabolisme, ces prélèvements, une fois secs, servent à la constitution d'échantillons hebdomadaires. Ces derniers sont analysés pour déterminer leurs teneurs en cendres, matières azotées totales ( $\mathrm{N} \mathrm{Kjeldahl} \times 6,25)$ et en cellulose brute Weende (cette dernière n'est faite que sur les échantillons des fourrages distribués). Ces mêmes analyses sont réalisées sur des échantillons prélevés à la mise en silo et représentatifs du fourrage ensilé. Enfin, sur deux échantillons secs du colza vert âgé de 90 jours, sont dosés quelques minéraux et oligoéléments. 
TABLF

Composition chimique, digestibilité, ingestibilité, valeur nutr Chemical composition, digestibility, voluntary intake, nutr

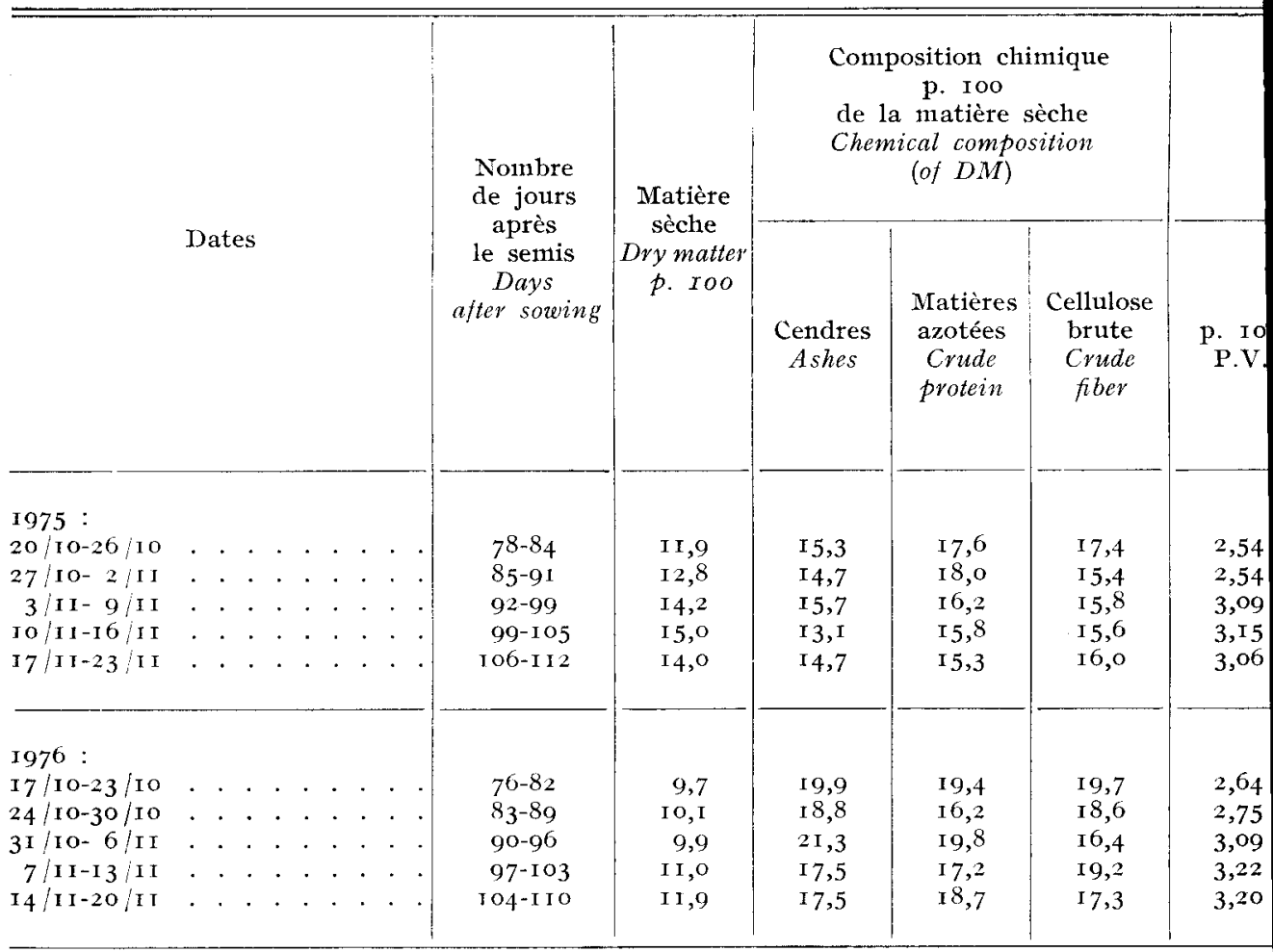

Pour chaque essai, les valeurs portant en indice les mêmes lettres ne sont pas significativement différent In each trial, the values accompanicd by the same letters are not significantly different.

Dans le cas des ensilages, pour chaque semaine de mesure, nous prélevons un échantillon représentatif de l'ensilage distribué aux moutons afin de doser :

- sur le produit frais, les matières azotées totales,

- sur les jus, le $\mathrm{pH}$, les bases azotées volatiles exprimées en $\mathrm{N}-\mathrm{NH}_{3}$ par microdiffusion (CoNwAy, I962) et les acides gras volatils. Le dosage des acides gras volatils est fait par chromatographie en phase gazeuse, sur colonne de verre de $3 \mathrm{~m}$ de longueur et $3 \mathrm{~mm}$ de diamètre interne; le support chromosorb W. 80-Ioo est imprégné de $25 \mathrm{p}$. roo de NPGA (N pentyl glycol adipate) et de $2 \mathrm{p}$. roo d'acide phosphorique. La température du four est de $130^{\circ} \mathrm{C}$ et celle de 1'injecteur de I $80^{\circ} \mathrm{C}$.

Les teneurs en ammoniaque et acides gras volatils permettent de corriger la teneur en matière sèche de 1'ensilage, selon la formule de FATIANOFF et GouET (1969) :

- matière sèche corrigée $=$ matière sèche non corrigée $\times \mathrm{Y}$ avec $\mathrm{Y}=\mathrm{I}+0,007 \mathrm{X}$ 
roduction à l'hectare du colza jourrager en vert

and dry matter harvested per hectare of fresh rape

\begin{tabular}{|c|c|c|c|c|c|c|c|c|c|}
\hline \multicolumn{3}{|c|}{$\begin{array}{l}\text { Matière sèche ingérée } \\
\text { Dry matter intake }\end{array}$} & \multicolumn{3}{|c|}{$\begin{array}{c}\text { Coefficient } \\
\text { de digestibilité } \\
\text { (p. 10o) } \\
\text { Digestibility coefficient }\end{array}$} & \multicolumn{2}{|c|}{$\begin{array}{l}\text { Valeur nutritive } \\
\text { par kg de } \mathrm{M} . \mathrm{s} . \\
\text { Nutritive value } \\
\text { (per kg of J.M.) }\end{array}$} & \multicolumn{2}{|c|}{ Production / ha } \\
\hline $\mathrm{n} \mathrm{kg} /$ & $\mathrm{P}^{0,75}$ & \multirow{2}{*}{$\begin{array}{l}\text { VEF } \\
\text { en } \\
\text { UF }\end{array}$} & \multicolumn{2}{|c|}{$\begin{array}{c}\text { Matière } \\
\text { organique } \\
\text { Organic matter }\end{array}$} & \multirow{2}{*}{$\begin{array}{l}\text { Matières } \\
\text { azotées } \\
\text { Crute } \\
\text { protein }\end{array}$} & \multirow{2}{*}{$\begin{array}{c}\text { C.F. } \\
\text { Breirem } \\
(f . U .)\end{array}$} & \multirow{2}{*}{$\begin{array}{l}\text { M.A.D. } \\
(\stackrel{g}{ }) \\
(D . C . P .)\end{array}$} & \multirow{2}{*}{$\begin{array}{l}\text { M.S. } \\
(\mathrm{t})\end{array}$} & \multirow{2}{*}{$\begin{array}{c}\text { U.F. } \\
\text { Breirem } \\
(F . U .)\end{array}$} \\
\hline $\begin{array}{l}\text { yenne } \\
\text { Lean }\end{array}$ & $\begin{array}{l}\text { C.V. } \\
\text { p. IOO }\end{array}$ & & $\begin{array}{l}\text { Moyenne } \\
\text { Mean }\end{array}$ & $\begin{array}{l}\text { C.V. } \\
\text { p. } 100\end{array}$ & & & & & \\
\hline $73,3^{a}$ & I 7 & $\mathrm{I}, 02$ & $83,7^{a}$ & 1,6 & $7^{8}, 9^{b}$ & $0,9 \mathrm{I}$ & I 39 & 2,3 & 2093 \\
\hline $73,5^{a}$ & I 2 & 1,00 & $82,6^{a}$ & 0,6 & $77,0^{a b}$ & 0,90 & I 39 & 2,6 & $234^{\circ}$ \\
\hline $91,6^{b}$ & 13 & 0,82 & $82,6^{n}$ & $\mathrm{I}, 5$ & $74,8^{a b}$ & 0,89 & $\mathrm{I} 2 \mathrm{I}$ & 2,9 & $25^{8 \mathrm{I}}$ \\
\hline $33,5^{b}$ & I 4 & 0,80 & $84,2^{a}$ & 0,8 & $75,9^{a b}$ & 0,94 & 120 & 3,4 & 3196 \\
\hline $2,9^{b}$ & 13 & $0,8 \mathrm{I}$ & $82,3^{n}$ & $\mathrm{I}, 4$ & $74,0^{a}$ & 0,89 & $\mathrm{II}_{3}$ & 3,3 & 2937 \\
\hline $7^{6}, 7^{a}$ & I 6 & 0,98 & $8 \mathrm{I}, 9^{\prime \prime}$ & 5,2 & $82,2^{a}$ & 0,83 & I 59 & 4,0 & 3320 \\
\hline $79,5^{a b}$ & 14 & 0,94 & $79,5^{a}$ & 4,2 & $76,7^{a}$ & 0,80 & I 24 & $4, \mathrm{~T}$ & 3280 \\
\hline $89,0^{b c}$ & I I & 0,84 & $83,9^{\prime \prime}$ & 2,3 & $82,6^{a}$ & 0,85 & 164 & $3, \mathrm{I}$ & 2635 \\
\hline $93,3^{c}$ & Io & 0,80 & $83,7^{a}$ & $\mathrm{I}, 4$ & $80, \mathrm{I}^{a}$ & 0,88 & I 38 & 2,9 & 2552 \\
\hline $93,9^{c}$ & Io & 0,80 & $82,5^{\prime \prime}$ & 2,2 & $8 \mathrm{r}, 9^{a}$ & 0,86 & I 53 & 3,0 & $25^{80}$ \\
\hline
\end{tabular}

- et $\mathrm{X}=$ quantité de composés volatils (acides gras volatils et ammoniaque) dosés sur le produit frais après macération et exprimés en p. Ioo de la matière sèche non corrigée. Le dosage des produits volatils n'est fait que sur le fourrage distribué mais la correction calculée est également appliquée aux refus.

\section{Résultats}

$$
\text { I. - Le fourrage vert }
$$

Teneur en matière sèche

Pour la même durée de végétation, la teneur en matière sèche (tabl. I) est sensiblement plus élevée en I975 (I 2 à I4 p. IOo) qu'en I976 (Io à I2 p. IOo). Cette teneur, variable d'un jour à l'autre en fonction des conditions clima- 
tiques, augmente toutefois légèrement au fur et à mesure du vieillissement de la plante.

\section{Composition chimique de la matière sèche}

Les teneurs en cendres, matières azotées totales et cellulose brute sont systématiquement plus élevées en I976 qu'en I975.

La teneur en cendres varie peu avec 1'âge du fourrage. Elle est élevée : $x_{4}, 7$ p. Ioo en I975, I9 p. Ioo en I976.

Le colza est riche en phosphore et surtout en calcium. La teneur en sodium est variable et elle est d'autant plus faible que celle du potassium est élevée. Les taux de cuivre et de zinc sont satisfaisants eu égard aux besoins des animaux (tabl. 2).

Dans nos conditions d'observation, il n'apparaît pas d'évolution des teneurs en matières azotées totales et cellulose brute du fourrage vert. Selon l'âge de la plante et 1'année de mesure, les teneurs en matières azotées totales sont comprises entre I5,3 et I9,8 p. Ioo, celles en cellulose brute varient entre I5,6 et I 9,7 p. Ioo.

TABLEAU 2

Composition minérale de la plante de colza fourrager

Mineral composition of rape

\begin{tabular}{|c|c|c|c|c|c|c|c|}
\hline \multirow{2}{*}{$\begin{array}{l}\text { Nombre de jours } \\
\text { après le semis } \\
\text { Days after soning }\end{array}$} & \multicolumn{5}{|c|}{$\begin{array}{c}\text { En } \mathrm{g} / \mathrm{kg} \text { de niatière sèche } \\
\quad \ln g / k g \text { dry matter }\end{array}$} & \multicolumn{2}{|c|}{$\begin{array}{c}\text { En mg/kg } \\
\text { de niatière sè̀che } \\
\text { In mg/kgdry matter }\end{array}$} \\
\hline & $P$ & $\mathrm{Ca}$ & $\mathrm{Mg}$ & $\mathrm{K}$ & $\mathrm{Na}$ & $\mathrm{Cu}$ & $Z n$ \\
\hline $\begin{array}{l}\text { 1975: } \\
85-9 \mathrm{I} \text { jours (days). }\end{array}$ & 5,7 & 17,3 & 1,2 & 33,6 & 0,4 & 8,4 & 47 \\
\hline $\begin{array}{l}\text { I976: } \\
\quad 90-96 \text { jours (days). }\end{array}$ & 5,5 & $\mathrm{I}^{2,4}$ & 1,9 & 45,4 & 1,5 & I 0,5 & 54 \\
\hline
\end{tabular}

\section{Ingestibilité}

De la $I^{\text {re }}$ à la $5^{\mathrm{e}}$ semaine de mesure, l'ingestibilité varie de 2,5 à $3,<\mathrm{kg}$ de matière sèche par Ioo $\mathrm{kg}$ de poids vif, soit de 73 à $94 \mathrm{~g}$ de matière sèche par $\mathrm{kg}$ $\mathrm{P}^{0,75}$ (tabl. I). En fait, elle augmente significativement pendant les deux premières semaines puis reste stable de la $3^{\mathrm{e}}$ à la $5^{\mathrm{e}}$. De plus, son coefficient de variation est élevé la ${ }^{r}$ re semaine. Il est donc possible de supposer que cette variation de l'ingestibilité est plus liée à l'insuffisance de la durée de la période d'accoutumance qu'à une variation de la composition chimique du fourrage. Les ingestibilités moyennes, calculées uniquement sur les trois dernières semaines, sont identiques en $\mathrm{I} 975$ et $\mathrm{I} 976$ et égales à $92 \mathrm{~g}$ de matière sèche par $\mathrm{kg} \mathrm{P}^{0,75}$. Pour cette période, la valeur d'encombrement du fourrage vert (VEF), exprimée en unité d'encombrement (UE), est égale à 0,82 . 


\section{Digestibilité}

La digestibilité de la matière organique du colza est élevée, de l'ordre de $\$ 2,5$ p. Ioo. Flle varie très peu d'une semaine à l'autre ou d'une année à l'autre (tabl. I).

La digestibilité des matières azotées est différente avec l'année. Elle est significativement inférieure $(\mathrm{P}<0,05)$ en $\mathrm{I} 975,76, \mathbf{I}$ p. roo en moyenne contre 80,7 en I976. Son évolution au cours du temps ne se fait pas de la même façon en 1975 et 1976 . La $\mathrm{I}^{\mathrm{re}}$ année, elle diminue significativement $(\mathrm{P}<0,05)$ de la $\mathrm{I}^{\mathrm{re}}$ à la $5^{\mathrm{e}}$ semaine de mesure, et passe de 78,9 à $74 \mathrm{p}$. I 00 . La $2^{\mathrm{e}}$ année, les variations ne sont pas significatives, la digestibilité moyenne étant égale à 80,7 p. Ioo.

\section{Valeur nutritive}

-- Cet essai ayant été réalisé en 1975 et 1976 , les mesures d'énergie brute et de solubilité de l'azote des fourrages n'ont pas été faites. La valeur nutritive est donc exprimée en U.F. Breirem et en M.A.I). par kg de matière sèche. Cependant les résultats obtenus dans le nouveau système d'évaluation de la valeur des aliments sont présentés dans le tableau 5 . La valeur énergétique du $\mathrm{kg}$ de matière sèche est égale en moyenne à 0,90 U.F. Breirem en I975, à 0,84 U.F. en I976. Cette différence s'explique par une teneur en cendres supérieure en I976 (tab1. I).

- En I975, la valeur azotée du colza vert diminue au fur et à mesure du vieillissement de la plante. Ia valeur du $\mathrm{kg}$ de matière sèche passe de I 39 à I $3 \mathrm{~g}$ de M.A.D. Cette évolution est due aux diminutions de la teneur et de la digestibilité des matières azotées totales.

- En 1976, il est beaucoup plus difficile de mettre en évidence l'influence de l'âge de la plante. La valeur azotée du $\mathrm{kg}$ de nuatière sèche de fourrage vert oscille entre 124 et I64 g de M.A.D.

\section{Production à l'hectare}

Selon les années, les zones de récolte dans la parcelle et le stade de récolte, la production de matière sèche par hectare est comprise entre 2,3 et 4 , I $t$ (tab1. I), ce qui représente 2000 à 3300 U.F. Breirem et 320 à $640 \mathrm{~kg}$ de matières azotées digestibles par hectare.

$$
\text { 2. - L'ensilage }
$$

\section{Conservation}

Les pertes enregistrées au cours de la conservation sont beaucoup plus élevées en 1976 (1u'en I975, respectivement 34,8 et I3,6 p. Ioo de la matière sèche mise en silo (tabl. 3 ).

Les mauvais résultats obtenus en I 976 peuvent avoir pour cause :

- la fairle teneur en matière sèche du fourrage vert à la mise en silo, ro.6 p. roo contre I3,7 p. Ioo en 1975.

- un apport insuffisant de conservateur, I,5 1 d'acide formique par tonne de foutrage. 
TABLEAU 3

Bilan de conservation des ensilages de colza Conservation of rape silages

\begin{tabular}{|c|c|c|c|c|c|}
\hline & \multicolumn{2}{|c|}{$\begin{array}{l}\text { Fourrage vert } \\
\text { Grem forage }\end{array}$} & \multicolumn{2}{|c|}{$\begin{array}{c}\text { l'ourrage après ensilage } \\
\text { Forage after silage }\end{array}$} & \multirow{2}{*}{$\begin{array}{c}\text { Pertes } \\
\text { de } \\
\text { matière sèche } \\
\text { Dry matter } \\
\text { losses } \\
\text { (p. Ioo) }\end{array}$} \\
\hline & $\begin{array}{l}\text { Matière sèclie } \\
\text { Iry matte' } \\
\text { (p. roo) }\end{array}$ & $\begin{array}{l}\text { Quantités de } \\
\text { matière sèche } \\
\text { mises en silo } \\
\text { Amoumts of dry } \\
\text { matter ensiled } \\
\text { (kg) }\end{array}$ & $\begin{array}{l}\text { Matière sèche } \\
\text { Dry matter } \\
\text { (p. Ioo) }\end{array}$ & $\begin{array}{c}\text { Quantités de } \\
\text { matière sèche } \\
\text { retirées du silo } \\
\text { Amounts of dry } \\
\text { motter desiled } \\
(\mathrm{kg})\end{array}$ & \\
\hline I975. . & 13,7 & I 466 & 17,4 & 1267 & I 3,6 \\
\hline 1976. & 10,6 & 2777 & 14,0 & 1810 & 34,8 \\
\hline
\end{tabular}

Toutefois, cela n'a apparemment pas et de conséquences sur la valeur qualitative de l'ensilage estimée par les teneurs en acide butyrique et azote ammoniacal qui restent très faibles (tabl. 4). L'ensilage s'est enrichi en matière sèche (3,3 points), en cendres et cellulose brute; la teneur en matières azotées totales a peu varié.

\section{Ingestibilité}

En I975, la quantité d'ensilage ingérée varie de 2,65 à $2,82 \mathrm{~kg}$ de matière sèche par Ioo $\mathrm{kg}$ de poids vif ou encore de 78,4 à $85,4 \mathrm{~g}$ de matière sèche par $\mathrm{kg}$ $\mathrm{P}^{0,75}$ soit en moyenne 0,90 unité d'encombrement (tabl. 4). Elle augmente significativement de la I $^{\mathrm{re}}$ à la $3^{\mathrm{e}}$ semaine de mesure. La dispersion des niveaux d'ingestion selon les animaux est assez semblable avec l'ensilage et le fourrage vert (mêmes valeurs des coefficients de variation). La conservation sous forme d'ensilage entraîne une diminution non significative (7,6 p. Ioo en moyenne) des quantités ingérées (comparaison effectuée entre les résultats de la $3^{\circ}$ semaine de mesure pour l'ensilage et la plante sur pied au stade ro2 jours.)

En I 976 , l'ingestibilité de l'ensilage ne varie pas de façon significative avec la semaine de mesure (tabl. 4). Elle est égale en moyenne à $2, \mathrm{I} \mathrm{kg}$ de matière sèche par roo $\mathrm{kg}$ de poids vif soit $62,2 \mathrm{~g}$ par $\mathrm{kg} \mathrm{P}^{0,75}$ ou $\mathrm{I}, 20$ unité d'encombrement. Ce niveau d'ingestion est donc nettement inférieur à celui en registré en 1975. De plus, les différences entre animaux sont plus marquées. Enfin la chute de consommation par rapport au fourrage vert est significative et atteint en moyenne $20,4 \mathrm{p}$. Ioo. Il faut remarquer que cet ensilage a été comparé au fourrage vert du même stade $(85 \mathrm{j})$. Or, si nous tenons compte du fait que, pendant cette semaine de mesure, l'ingestion du vert n'avait pas encore atteint sa valeur maximale, la baisse d'ingestion pourrait dépasser $30 \mathrm{p}$. Ioo. 


\section{Digestibiliti}

En I 975 , le coefficient de digestibilité de la matière organique ne varie pas significativement avec la semaine de mesure; il est en moyenne égal à 8o,8 p. Ioo (tabl. 4). Par rapport au fourrage vert du même âge, la diminution de la digestibilité de la matière organique est d'environ 3,4 points. La digestibilité des matières azotées du fourrage ensilé reste inférieure à celle de l'aliment en vert de I,4 à 5,8 points. Elle évolue avec la semaine de mesure, elle est significativement plus élevée la $\mathrm{I}^{\mathrm{rC}}$ semaine. Cela peut être mis en relation avec un plus faible niveau d'ingestion et une teneur en matières azotées légèrement plus élevée au cours de cette $\mathrm{I}^{\mathrm{re}}$ semaine.

En I 976, la digestibilité de la matière organique n'évolue pas avec la semaine de mesure. Elle est en moyenne égale à 8 I,6 p. Ioo (supérieure de 0,8 point à celle de r975). Eille est plus élevée que celle du fourrage vert avant ensilage $\left(79,5 \mathrm{p}\right.$. IOo). Toutefois, cette dernière est obtenue au cours de la $2^{\mathrm{e}}$ semaine de mesure sur le vert période où les différences entre moutons étaient encore importantes (coefficient de variation : 4 à 5 p. IOo). Nous avons montré que la digestibilité du fourrage vert n'évolue pas dans le temps. Il est donc possible de comparer la digestibilité de l'ensilage à la moyenne des digestibilités obtenues sur les 5 semaines de mesure du fourrage vert, soit $82,3 \mathrm{p}$. I oo. Dans ce cas, la conservation par ensilage fait diminuer la digestibilité de la matière organique d'environ 0,7 point. Comme, en I975, le coefficient d'utilisation digestive des matières azotées diminue significativement de la $I^{\text {re }}$ à la $3^{\text {e }}$ semaine de mesure. Comparé à celui du fourrage vert mesuré sur 5 semaines $(80,7$ p. I00), il diffère de $+0,1$ à $-5,7$ points.

\section{Taleur nutritive}

La valeur énergétique moyenne de l'ensilage de colza est égale à 0,83 U.F. Breirem par $\mathrm{kg}$ de matière sèche. La teneur en M.A.D. du $\mathrm{kg}$ de matière sèche est comprise entre i Io et I $40 \mathrm{~g}$. Comme pour le fourrage vert, les valeurs calculées en U.F.I. et U.F.V. sont données dans le tableau 5 .

\section{Discussion}

- Les teneurs en cendres, matières azotées totales et cellulose brute du colza I 976 sont supérieures à celles du colza I975. Cela peut s'expliquer en partie par la fertilisation azotée plus importante, appliquée en I976. Sur ray-grass anglais et prairies permanentes, une augmentation de la fumure azotée diminue la teneur en matière sèche, augmente significativement les teneurs en matières azotées totales et plus faiblement les teneurs en cendres et cellulose brute (DEMARQUII,Y, I970). Elle a une action peu marquée sur la digestibilité de la matière organique et accroît significativement celle des matières azotées.

La teneur en cellulose brute, I6 à i 8 p. Ioo de la matière sèche, est faible, le colza est exploité à un stade végétatif et non à la floraison. Deux variétés de printemps, Liho et Rapso, récoltées à la floraison, ont des teneurs en cellulose de l'ordre de 30 p. roo (PI.Ancquaert, I972). Par contre, Arvor, variété d'hiver, 
TABI.

Caracteristiques de la conservation, composition chimique, digestib Fermentation characteristics, chemical composition, digestib

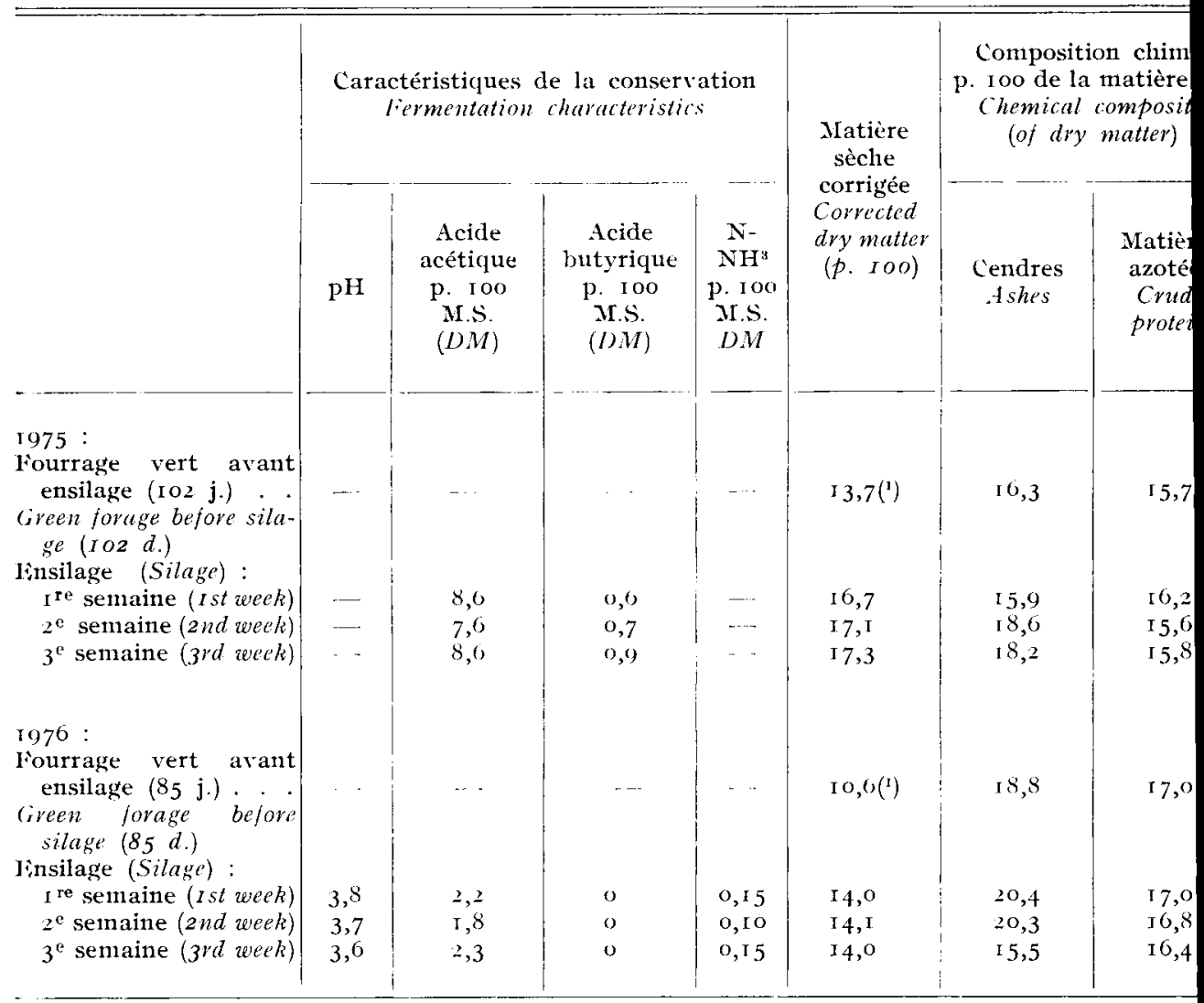

Pour chaque essai, les valeurs portant en indice les mèmes lettres ne sont pas significativement différe In each trial, the values accompanied by the same letters are not significantly differnt.

(I) Ia correction ne s'applique pas au fourrage vert.

The correction does not concern green forage.

semée au printemps, exploitée au même âge mais au stade végétatif contient 20 p. IOO de cellulose brute (PLANCQUAERT, I972). I)e même, la variété Liho, exploitée avant la floraison, ne contient que 20 p. I oo de cellulose brute (BECKER et NEHRING, I 969). Les teneurs en matières azotées totales, variant entre I5.3 et I9,8 p. Ioo selon l'année et le stade de récolte, sont sensiblement plus élevées que les valeurs (I2 à I3 p. Ioo) obtenues par PLANCQUAER'T (I972) sur colzas de printemps à la floraison ou sur Arvor semé au printemps. Elles sont proches des valeurs rapportées par BECKER et NEHRING ( 969 ) pour la variété Liho récoltée avant floraison.

- Le colza vert est apprécié par les animaux; son ingestibilité, $92 \mathrm{~g} / \mathrm{kg}$ $P^{0,75}$, est élevée, proche de celle de la féverole utilisée en vert ('TIssERAND et Roux, I976). Il est très digestible, la digestibilité de la matière organique est 
tibilité et valeur mutritive du colza fourrager apris consilage

atary intakc and nutritive value of rape silage

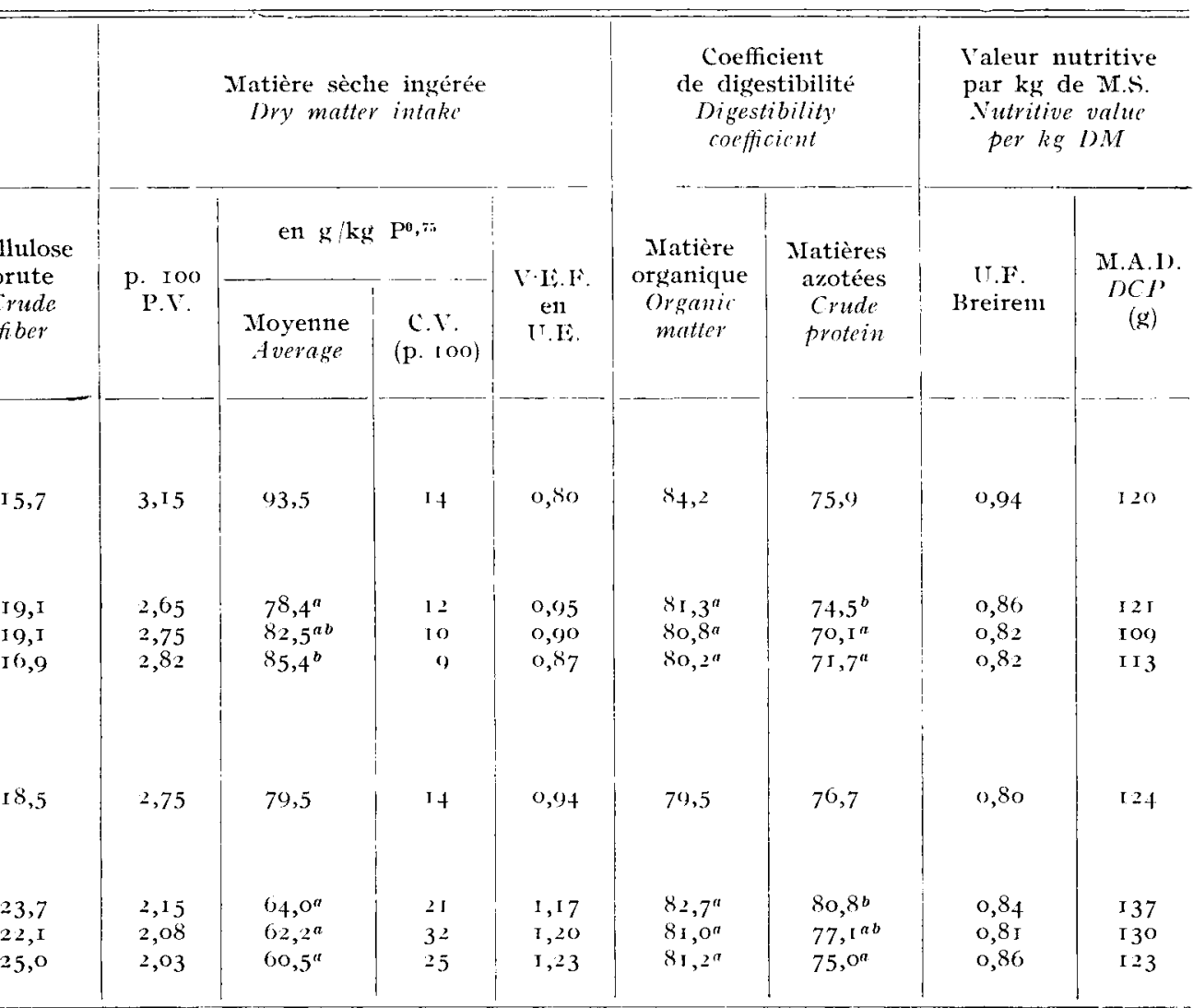

en moyenne égale à $82,7 \mathrm{p}$. Ioo (de 75 à $80 \mathrm{p}$. Ioo pour Piancouafrt, I972). Ainsi, le colza en vert a une bonne valeur énergétique, 0,84 à 0,90 U.F. Breirem par $\mathrm{kg}$ de matière sèche, sensiblement supérieure à celle des colzas de printemps exploités en début floraison (I.N.R.A., I 978; PLANCQUAERT, I972). Ces différentes caractéristiques de composition et de valeur alimentaire n'évoluent pas significativement avec l'âge de la plante, l'exploitation de ce fourrage peut donc être étalée dans le temps. Ira valeur azotée aurait peut-être tendance à diminuer avec le vieillissement de la plante, ce phénomène n'a toutefois été mis en évidence qu'au cours de la I $^{\text {re }}$ année.

- Les animaux recevant le colza vert à volonté ont ingéré en moyenne 3 U.F. par roo $\mathrm{kg}$ de poids vif. Cette valeur est largement supérieure aux besoins d'entretien de ce type d'animal et explique les gains journaliers de poids vifs 


\section{TABLEAU 5}

Valeurs énergétique et azotée du colza vert et de l'ensilage exprimées dans le système d'évaluation I.N.R.A. 1978

Nutritive value of fresh or ensiled rape in the I.N.R.A. $7^{8}$ method of evaluation

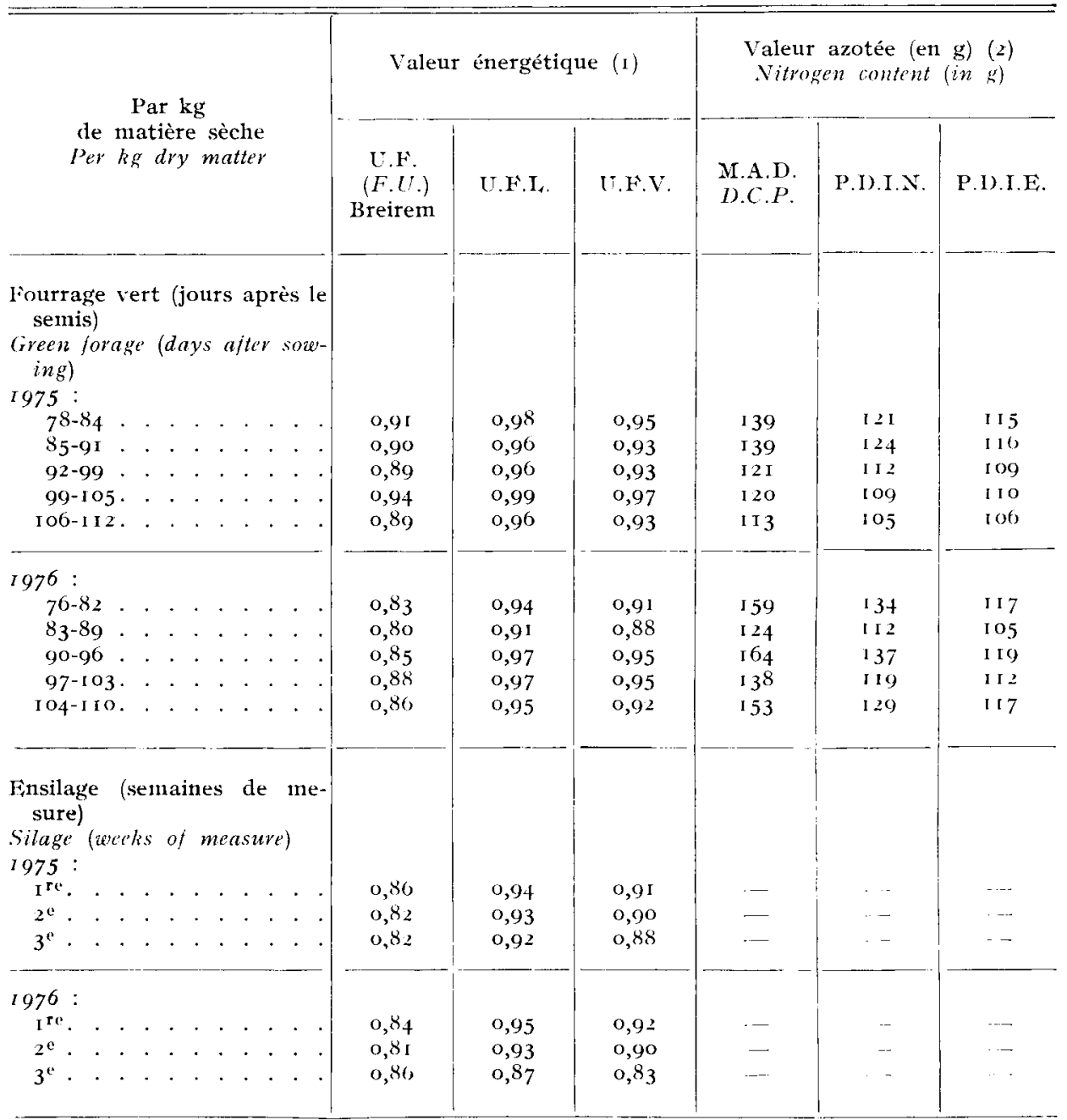

(1) Pour calculer la valeur énergétique du fourrage en vert et de l'ensilage, nous avons retenu les valeurs suivantes d'apress INRA, 1978 (p. 479, 480, 53I) :

For calculating the energy ralue of green forage, tee used the folloning values according to I.N.R.A., 1978 (p. $479,480,53 \mathbf{1}$ ).

a- Energie brute : $4080 \mathrm{kcal} / \mathrm{kg}$ MS.

I)E - I:D $=\mathrm{FB}(\mathrm{I}, 0087 \mathrm{~d} \mathrm{MO}-0,0377)$

$\frac{\mathrm{IEM}}{\mathrm{ILD}}=0,8286-0,0000877 \mathrm{CB}-0,000174 \mathrm{MAT}+0,0243 \mathrm{NA}$ avec $\mathrm{NA}=\mathrm{I}, 7$

(2) Pour l'expression de la valeur azotéc. les données bibliographiques n'existent que pour les fourrages verts et sont les suivantes : solubilité égale à 0,40 et dr égale à 0,90 d'après INRA, I978 (p. 48.5-488).

For expressing the nitrogen value, the data available in the literature only concern green forages and are the following: solubility $=0.40$ and $d r=0.90$ according to I.N.R.A., $1978(p .485-488)$. 
élevés enregistrés : $350 \mathrm{~g}$ et $150 \mathrm{~g}$ en moyenne respectivement en 1975 et I 976 .

- La production de matière sèche à 1'hectare est relativement faible; elle varie de 2,3 à 4,I t selon l'année et l'âge de la plante. Toutefois, il s'agit d'une culture dérobée. En culture irriguée, Hugues (I962) récolte 5 tonnes de matière sèche à l'hectare avec la variété de printemps Liho, semée en août et récoltée à la floraison en septembre. Des productions du même ordre sont données par C.E.T.I.O.M. (I973), PlancQuaerT (I97I et I972), Piccioni (Ig65). Certaines variétés d'hiver récoltées à la floraison produisent jusqu'à 9 tonnes (PLANCQUAERT, r972). Enfin, des variétés d'hiver semées au printemps seulement et utilisées. 60 à roo jours plus tard au stade végétatif sont généralement plus productives. que les variétés de printemps semées à la même époque et exploitées à la floraison (PlancouaerT, I97I et I972).

- Les quantités d'ensilage ingérées sont très différentes selon 1'année. En 1976, la teneur en matière sèche est de I0,6 p. I oo à la mise en silo (I3,7 p. IOo en I975) et de I4 p. Ioo à la sortie du silo (I7 p. Ioo en I975). Cette faible teneur en matière sèche ainsi qu'une dose de conservateur diminuée peuvent expliquer l'ingestibilité moindre enregistrée au cours de $1 \mathrm{a} 2^{\mathrm{e}}$ année.

La conservation par ensilage entraîne une légère diminution de digestibilité; ce phénomène est normal. La valeur énergétique de l'ensilage $(0,83$ U.F. Breirem par $\mathrm{kg}$ de matière sèche) est inférieure à celle du fourrage vert. S'il paraît effectivement possible de conserver par ensilage un colza fourrager, il est toutefois souhaitable de n'utiliser qu'une plante ayant une teneur en matière sèche suffisante. Or, il est en général assez difficile de l'obtenir étant donné la période de végétation de cette culture en dérobé (août à novembre).

In conclusion, le colza fourrager cultivé en dérobé se prête tien à une utilisation en vert; l'exploitation peut facilement être étalée dans le temps, dans la mesure où les conditions atmosphériques le permettent. Cet étalement rend alors moins utile le recours à l'ensilage.

Accepté pour publication en juin 1978.

\section{Remerciements}

Nous tenons à remercier M. J. PICARD et le personnel de la Station I.N.R.A. d'Amélioration des Plantes de Dijon qui ont bien voulu assurer la mise en culture du colza.

\section{Summary}

Feeding value of catch-crop rape (Brassica napus, var. oleifera) offered to sheep, fresh or silaged

Catch-crop rape of the Tantal variety with vegetation cycle of 90 days was sown at the beginning of August in 1975 and 1976 in the Côte-d'Or.

Digestibility and intake level of green forage harvested between the $\mathrm{I}$ ith and the $\mathrm{I} 6 \mathrm{th}$ week of vegetation and of silage made the 85 th and rooth day of vegetation were determined on sheep.

During the five weeks, the dry matter content of the plant increased from 12 to I 5 p. Ioo in 1975 , from 10 to 12 p. Ioo in 1976 . Chemical composition of dry matter was:

- in 1975,15 p. Ioo ashes, I6 p. roo crude fiber, I6 p. roo crude protein; 
- in 1976 , 19 p. 100 ashes, 18 p. I00 crude fiber, 18 p. 100 crude protein.

Sheep ingested $92 \mathrm{~g} \mathrm{DM} / \mathrm{kg} \mathrm{W}^{0,75}$. The digestibility of the organic matter (about $82-$ 83 p. Ioo) remained constant with the age of the plant. In 1975, the digestibility of the crude protein decreased with the age of rape (from 79 to $74 \mathrm{p}$. 10o). On the other hand, in 1976 , it was higher than in 1975 (on an average $9 \circ \mathrm{p}$. roo) and was independant of the age of the plant.

The energy value ranged between 0.85 and 0.90 Feed Units (Breirem) per kg DM. The digestible crude protein content ranged between II and I60 g per kg DM.

The silage characteristics were good. Losses in the silo represented i 4 p. roo of the dry matter content in 1975 and 35 p. roo in 1976 . Silage caused a small reduction in the digestibility of the organic matter and a greater and more variable decrease in the feed intake (7.6 p. Ioo in $1975,20 \mathrm{p}$. 100 in 1976 ). The feeding value of rape silage was 0.83 Feed Units (Breirem) and $\mathrm{I} I \mathrm{O}-\mathrm{I} 4 \mathrm{O} \mathrm{g}$ of digestible crude protein per $\mathrm{kg} \mathrm{DM}$.

\section{Références bibliographiques}

Becker M., NhHring K., I969. - Handbuch der Futter Mittel. Eister Band 151-i53, Paul Parey, Berlin.

C.E.T.I.O.M., 1973. - Colza fourrager. Bulletin du C.E.T.I.O.M., 50, 16-18.

Conway E. J., 1962. - Microdiffusion analysis and volumetric error, ed. 5. Crossby. Lnokwood and Son, London.

Demarquiliy C., I97o. Influence de 1a fertilisation azotée sur la valeur alimentaire des fourrages verts. Ann. Zootech., 19, 423-437.

Fatranofi Nathalie, Govet Ph., i969. Relation permettant de corriger rapidement et avec précision la matière sèche des ensilages séchés à l'étuve. Ann. Zootech., 18, 407-418.

HUGUes P., 1962. Essais de fourrages dérobés d'été en culture irriguée dans le midi de la France. Bull. Tech. Ing. Sevv. Agric., 171, 557-568.

I.N.R.A., 1978 . Alimentation des ruminants. Ed. I.N.R.A. Publications (Route de Saint-Cyr), 78000 Versailles, $479-488$.

PICCIONI M., I965. Dictionnaive des aliments pour les animaux; éd. Ed. agricole, III-II3.

PLANCQUaERT Ph., I97I. Étude comparative de plantes fourragères annuelles. $1^{\text {re }}$ partie : Semis de printemps et début d'été. Institut Technique des Céréales et des Fourrages, $3 \mathbf{I}$ p.

Plancouakr Th, 1972. Étude comparative de plantes fourragères annuelles $2^{\circ}$ partie : Semis d'automne. Institut Technique des Céréales et des Fourrages, 15 p.

Plancquafir Ph., 1972. Iitude de quelques variétés de colza fourrager. Institut Technique des Céréales et des Fourvages, $15 \mathrm{p}$.

Tisserand J. L. et Rovx M., r976. Valeur alimentaire de la plante entière de féverole (Vicia Faba L.) en vert et après ensilage. Ann. Zootech., 25, ז69-ז8o. 